\title{
A COMPARATIVE APPROACH TO TOPICAL CYCLOSPORINE THERAPY
}

\author{
DAVID L. WILLIAMS \\ Newmarket
}

\begin{abstract}
SUMMARY
Topical cyclosporine has been used by veterinary ophthalmologists since 1989 for the treatment of ocular surface inflammatory disease and keratoconjunctivitis sicca (KCS). As well as ameliorating clinical signs of ocular surface lymphocyte-driven inflammation in the dog, cat and horse, topical cyclosporine significantly raises tear production in both normal and KCS-affected animals. A licensed ointment preparation of $0.2 \%$ cyclosporine, Optimmune (Schering-Plough), is now available for administration to dogs. In this paper we examine the mechanisms by which cyclosporine exerts both its immunomodulatory and its lacrimogenic actions. The pharmacokinetics of topical cyclosporine are examined to determine whether these effects are truly local or are influenced by generalised immunosuppression caused by systemic absorption of topically applied drug. The paper reviews the few side effects of cyclosporine preparations in the experience of veterinary ophthalmologists and the experimental evidence which appears to implicate the vehicle rather than the active agent cyclosporine as causing many of these effects. Given that topical cyclosporine has been so widely accepted as a valuable ophthalmic preparation in the veterinary world and licensed as such, it is surprising that human ophthalmologists have not employed the drug to the same extent for conditions from vernal keratoconjunctivitis to Sjögren's syndrome.
\end{abstract}

Cyclosporine was first isolated in the early 1970s as a product of the fungus Tolypocladium inflatum. ${ }^{1}$ Its mild antifungal actions soon paled into insignificance compared with profound anti-inflammatory effects. ${ }^{2}$ These have become the pivotal focus of both the clinical application of systemically administered cyclosporine in transplant immunology ${ }^{3}$ and research investigating mechanisms of lymphocyte action. ${ }^{4}$

Correspondence to: David L. Williams, MA, VetMB, PhD, CertVOphthal, MRCVS, Unit for Comparative Ophthalmology, Centre for Small Animal Studies, Animal Health Trust, PO Box 5, Newmarket, Suffolk, UK. Tel: +44 (0)1638 661111. Fax: +44 (0) 1638555600 .
Oral cyclosporine was soon used as a key drug in the prevention of transplant rejection ${ }^{5}$ and also to treat autoimmune disease. ${ }^{6,7}$ Systemic cyclosporine was reported to be valuable in experimental models of uveitis ${ }^{8}$ and in sight-threatening posterior uveitis in man. ${ }^{9}$ Topical cyclosporine was first used to prevent corneal graft rejection. ${ }^{10,11}$ Other indications for topical use in man include Mooren's ulcer, ${ }^{12}$ vernal keratoconjunctivitis, ${ }^{13}$ ligneous conjunctivitis ${ }^{14}$ peripheral rheumatoid ulceration ${ }^{15}$ and other ocular surface inflammatory disease. ${ }^{16}$ The ameliorative effects of topical cyclosporine in these inflammatory ocular surface disorders are readily explicable through direct effects on lymphocyte action.

Is the same spectrum of effects seen in domestic animals? Ocular surface inflammatory disease is seen in many domestic animals as discussed below. Cyclosporine has ameliorative effects in some of these diseases but not in all. The most interesting perspective from a comparative viewpoint is the beneficial effects of topical cyclosporine in canine keratoconjunctivitis sicca (KCS), with important implications for human Sjögren's syndrome patients. The mechanism of cyclosporine's lacrimogenic activity remains unclear, but there is no doubt that the drug does increase tear production in experimental animals, in companion animals and in man. Other questions remain with regard to the pharmacokinetics of topical cyclosporine from a theoretical aspect, and patient tolerance of different formulations in practice.

A licensed product (Optimmune, $0.2 \%$ cyclosporine ointment. Schering Plough, Welwyn, Herts, UK) is now available in the veterinary field for use in KCS and ocular surface inflammatory disease, but such a preparation has yet to reach the human pharmacy. For once veterinary ophthalmology can consider itself ahead of its human cousin! 


\section{MECHANISM OF ACTION OF CYCLOSPORINE}

For a drug so widely used in human medicine, it may seem surprising that the mechanism of immunosuppression caused by cyclosporine is still imperfectly understood. Several clues as to the mechanism of drug action have come from studies investigating intracellular molecular interactions of cyclosporine. Comparisons between cyclosporine, its immunosuppressive cousins FK-506 and rapamycin and nonimmunosuppressive analogues such as 506-BD and L-6835,818 have allowed researchers to determine which of these interactions are immunosuppressive. It is now known that the major site of immunosuppressive drug action is the inhibition of lymphokine secretion by $\mathrm{T}$ lymphocytes. This reduction in production of a group of lymphokines including interleukins 2 and 3 (IL-2, IL-3), tumour necrosis factor alpha $(\mathrm{TNF}-\alpha)$ and interferon-gamma is caused by the blockade of lymphokine gene transcription. The inhibition of mRNA production is related to interference with the synthesis or transport of transcriptional promoters such as NF-AT. ${ }^{17}$ NF-AT is produced early in $\mathrm{T}$ cell activation and binds to regulatory regions upstream of genes coding for molecules such as IL-2. ${ }^{18} \mathrm{NF}-\mathrm{AT}$ is a subunit of a protein complex essential for the transcription of the IL-2 gene. It exists as a cytosolic component NF-ATc which, when dephosphorylated, can move into the nucleus where it binds to the IL-2 promoter region. This critical dephosphorylation of NF-ATc occurs under the influence of calcineurin and is prevented by cyclosporine. ${ }^{19}$

The action of cyclosporine on calcineurin involves several intermediate steps. Cyclosporine binds to a cytosolic protein cyclophilin, one of a group of intracellular proteins now known as immunophilins. FK-506 and rapamycin bind to another immunophilin known, rather unimaginatively, as FK binding protein (FKBP). While FKBP has no sequence homology with cyclophilin and does not bind cyclosporine, both cyclophilin and FKBP share peptidyl-prolyl cis-trans isomerase (PPI) activity. This isomerase action is critical in the folding of newly transcribed polypeptides and possibly also in protein stabilisation. Binding to these molecules or inhibition of their PPI effect cannot, however, be the mechanism of immunosuppression of cyclosporine or FK-506 since the non-immunosuppressive analogues also bind and act as PPI inhibitors. ${ }^{20}$

It was hypothesised, however, that cyclophilin and FKBP have a role when bound to an intracellular kinase or phosphatase, forming a physiologically regulated enzyme complex. The action of cyclosporine, FK-506 or rapamycin cannot, however, be by preventing complex formation, since the concentration of drug required for immunosuppression is much smaller than the concentration needed to block all available cyclophilin or FKBP molecules. Instead the drugs would, in this model, exert their actions by forming a complex which alters enzyme activity. Cyclosporine-cyclophilin and FK-506-FKBP complexes have indeed been shown to bind to, and inhibit, the phosphatase calcineurin. ${ }^{21}$ Since NF-ATc dephosphorylation is thus prevented the molecule cannot be transported into the nuclear compartment where it would have access to transcriptional regulating domains upstream of cytokine genes. ${ }^{22}$ It is in this rather convoluted manner that cyclosporine has its action inhibiting lymphocyte activity.

Cyclosporine also interacts with calmodulin, binding to a hydrophobic pocket on the molecule, a feature shared with a number of calmodulin antagonists. $^{23}$ Given that calcineurin is regulated by calmodulin, the calmodulin-cyclosporine interaction may be important in drug action. Since, however, calmodulin binding is a characteristic of non-immunosuppressive as well as immunosuppressive cyclosporine analogues there is still debate over its role in the drug's immunomodulatory actions.

Many of the immunomodulatory effects of cyclosporine relate to inhibition of lymphokine production, although other areas of lymphocyte activity are also affected. Cyclosporine inhibits the release of granule-associated serine esterase important in cytotoxic $\mathrm{T}$ lymphocytes and particularly in polymorphonucleocytes. $^{24}$ Activation-driven apoptosis is also inhibited. $^{25}$ Significantly both of these involve intracellular calcium influx.

The relevance of all this basic science to the clinical use of topical cyclosporine might well be questioned. Yet, as will be discussed below, another of the key therapeutic effects of topical cyclosporine is to increase tear production. At present our understanding of the mechanisms of lacrimogenesis by cyclosporine are at the same stage that mechanisms of immunosuppression were 10 years ago. The myriad of molecular interactions of the drug show the difficulty of pinpointing the site of action of cyclosporine with regard to lacrimogenesis. Further research is needed using cyclosporine and its analogues, those both with and without immunomodulatory action, to probe mechanisms of lacrimation in the same way as they have been used to map mechanisms in $\mathrm{T}$ cell function.

\section{TOPICAL CYCLOSPORINE AS A LACRIMOGENIC AGENT}

This second action of cyclosporine might come as rather a surprise after the emphasis on immunosuppressive effects. Cyclosporine increases tear production in dogs with KCS (Fig. 1), a disease similar to the ocular manifestations of Sjögren's syndrome in man. One might suppose that the initial reason for 


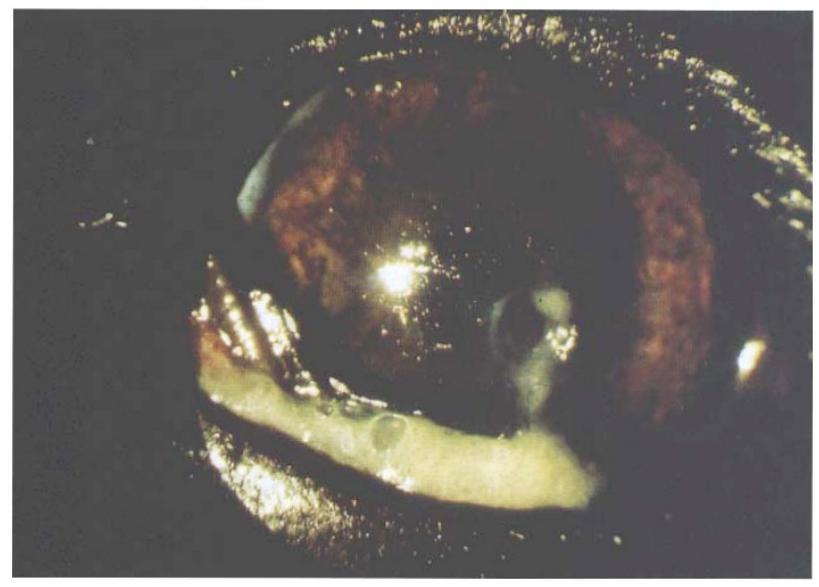

Fig. 1. Canine keratoconjunctivitis sicca.

choosing topical cyclosporine as a drug for use in canine KCS was because of the condition's presumed autoimmune nature. The immunohistological features of canine KCS involve lymphocytic infiltration of the lacrimal gland, ${ }^{26}$ as does Sjögren's syndrome in $\operatorname{man}^{27}$ and similar conditions in rodent models. ${ }^{28}$ While the development of such a train of thought from histological findings to therapeutic modality would appear scientifically justified, historically this was not the initial reason for using cyclosporine in canine KCS. Dr Renee Kaswan, the originator of cyclosporine treatment for canine KCS, had evidence of increased tearing in a friend treated systemically

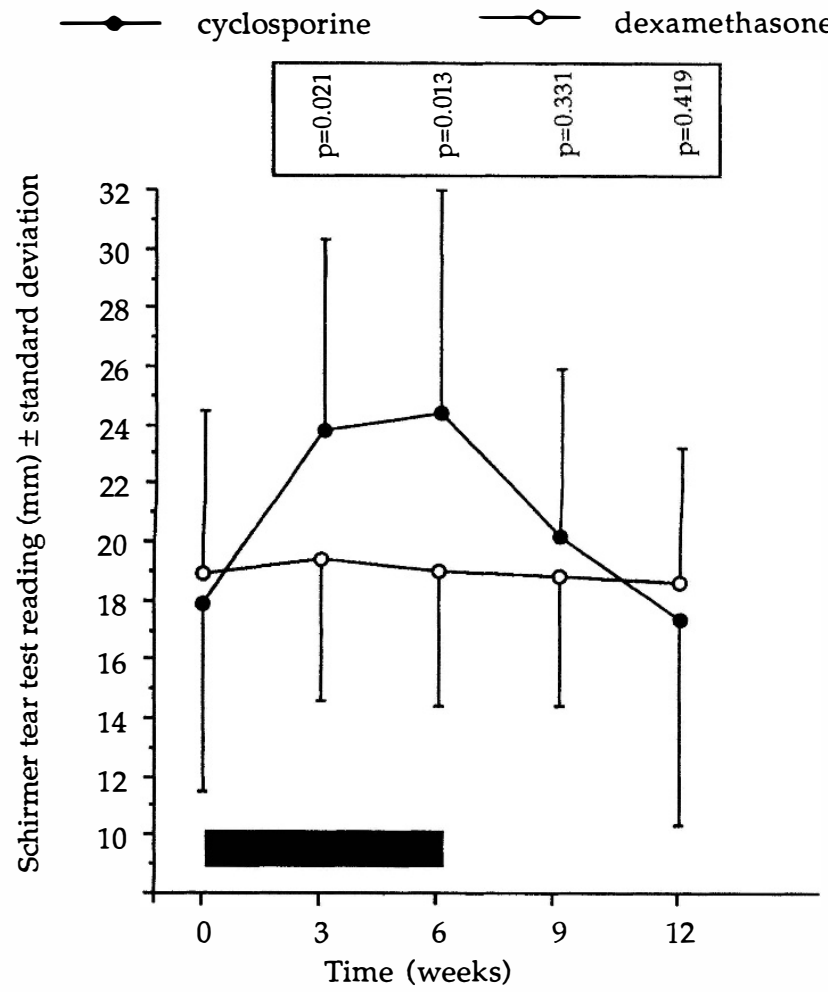

Fig. 2. Schirmer tear tests readings in 30 dogs with normal tear production given $0.2 \%$ topical cyclosporine ointment for 6 weeks. with cyclosporine after a kidney transplant ( $R$. Kaswan, personal communication). This individual finding was confirmed subsequently by other work$\mathrm{ers}^{29}$ and prompted Kaswan to investigate the use of topical $2 \%$ cyclosporine in dogs where previous treatment had relied on regular medication with artificial tear preparations, not ideal in a canine patient.

Kaswan was the first to show that topical cyclosporine has a marked lacrimogenic effect in the $\operatorname{dog}^{30}$ and these results have been repeated in other species: topical cyclosporine has been used successfully in horses with $\mathrm{KCS}^{31,32}$ and in cats in this author's experience, although KCS is rare in both these species.

The lacrimogenic effect occurs not only in dogs with KCS but also in normal animals. Fig. 2 shows Schirmer tear test readings in dogs treated with $0.2 \%$ cyclosporine ointment (Optimmune, Schering Plough) twice daily in the present author's study of dogs with chronic superficial keratitis. ${ }^{33}$ These animals exhibited immune-mediated corneal pathology but no lacrimal gland abnormalities and thus had normal tear production. Schirmer tear test readings, normally $18.3 \pm 3.4 \mathrm{~mm} \mathrm{~min}{ }^{-1}$ in the 30 dogs involved, increased by $5.7 \mathrm{~mm}$ while cyclosporine was used but no significant change was observed with the use of topical $0.1 \%$ dexamethasone. These differences were significant during treatment as demonstrated by an analysis of variance presented as $p$ values in Fig. 2. Fig. 3 shows Schirmer tear test

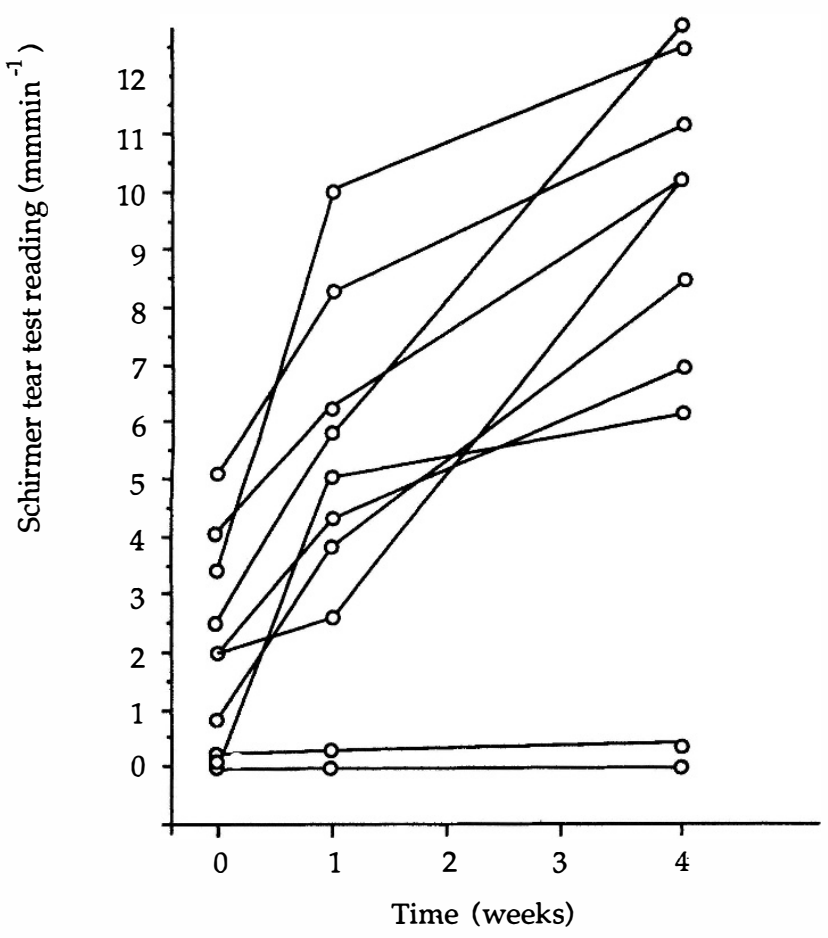

Fig. 3. Schirmer tear test readings in 10 dogs with keratoconjunctivitis sicca treated with $0.2 \%$ topical cyclosporine ointment. 
readings in 10 dogs presented to our hospital recently with KCS. In 7 dogs with low but measurable lacrimation, cyclosporine gave significant increases in tear production. Two animals with zero Schirmer readings showed no increase in lacrimation with cyclosporine while one animal with no measurable tear production did respond. This small group of dogs are typical of canine KCS cases, where the majority respond well but a small number fail to respond. It is presumed that the non-responders are cases in which gland atrophy or scarring has progressed to a stage in which no functional lacrimal tissue remains. Even so there are a number of dogs with zero Schirmer readings in which cyclosporine produces measurable tearing either immediately after commencing treatment, or more usually after a period of twice daily medication.

These results confirm the findings of Kaswan's group $^{30}$ who demonstrated an increase in Schirmer tear test readings in dogs with KCS from $3.5 \pm 4.6$ $\mathrm{mm} \mathrm{min}^{-1}$ before treatment with $2 \%$ topical cyclosporine to $12.5 \pm 6.5 \mathrm{~mm} \mathrm{~min}^{-1}$. Normal beagles with readings of $19.2 \pm 3.0 \mathrm{~mm} \mathrm{~min}^{-1}$ showed an increase to $25.8 \pm 2.9 \mathrm{~mm} \mathrm{~min}^{-1}$. These results show that cyclosporine has lacrimogenic effects in the normal as well as the KCS-affected animal. Other evidence suggests that the lacrimogenic actions do not relate directly to an immunosuppressive action of cyclosporine, since other immunosuppressive agents given topically do not result in an increase in lacrimation.

Having said that, there is likely to be an ameliorative effect on tear production by reducing autoimmune lacrimal gland destruction in cases in animals and man where this is the cause of KCS. The MRL/MP-1pr/1pr mouse with its defective lymphocytic apoptosis ${ }^{34}$ develops an autoimmune disease with lymphadenopathy, glomerulonephritis and serologic disturbances together with ocular and lacrimal gland pathology which is a good model of Sjögren's syndrome. One study reported cyclosporine to worsen lacrimal gland pathology in these mice with $\mathrm{CD}^{+}$lymphocytes replaced with $\mathrm{CD} 8^{+}$cells even where systemic autoimmune pathology was ameliorated. ${ }^{35}$ Here tear production was reduced by cyclosporine therapy by implant. Similar results were shown for salivary gland immunopathology in human Sjögren's syndrome, where the drug significantly worsened gland inflammation. ${ }^{36} \mathrm{~A}$ more recent report finds systemic cyclosporine to be efficacious in reducing severity of both ocular and lacrimal gland lesions in MRL/MP-1pr/1pr mice although tear volumes were not measured in this study. ${ }^{37}$ The relative roles of immunosuppression and direct lacrimogenesis in ameliorating keratoconjunctivitis sicca in these mice are unclear, but the action of cyclosporine in normal dogs would appear to suggest that a direct effect is more likely to be occurring rather than one secondary to immunomodulation of inflammatory disease.

While Kaswan initially used $2 \%$ cyclosporine in olive oil, subsequent American studies used other oils as diluting vehicles and reduced the cyclosporine concentration to $1.5 \%$ and then $1 \%{ }^{38}$ The present author began investigating the use of topical cyclosporine in 1990 and found that $0.2 \%$ cyclosporine in corn oil appeared to be as lacrimogenic as $2 \%$ solution. This prompted a small dose-response study with somewhat surprising results (Fig. 4). Taking the mean values of improvement in Schirmer tear test reading for a group of dogs gives a standard dose-response curve (heavy line, Fig. 4). But for individual animals there seems a sharp cut-off between maximal improvement and no response whatsoever. The concentration at which this cut-off occurs seems different for each dog, resulting in the large error bars in a standard dose-response curve at around these concentrations. The action of topical cyclosporine in the majority of dogs at one-tenth of the concentration originally used is now widely recognised, and now $0.2 \%$ ointment is licensed and marketed for veterinary use.

What do these findings in normal and KCSaffected dogs suggest concerning mechanisms underlying the lacrimogenic action of cyclosporine? Initial suggestions that cyclosporine acted predominantly by reducing the lymphocytic infiltrate in canine KCS are unlikely to be correct. Firstly the rapid lacrimogenic action of the drug occurs faster than resolution of the inflammatory infiltrate in affected glands. Secondly the drug increases tear production in normal animals where a pathological lacrimal gland lymphocytic

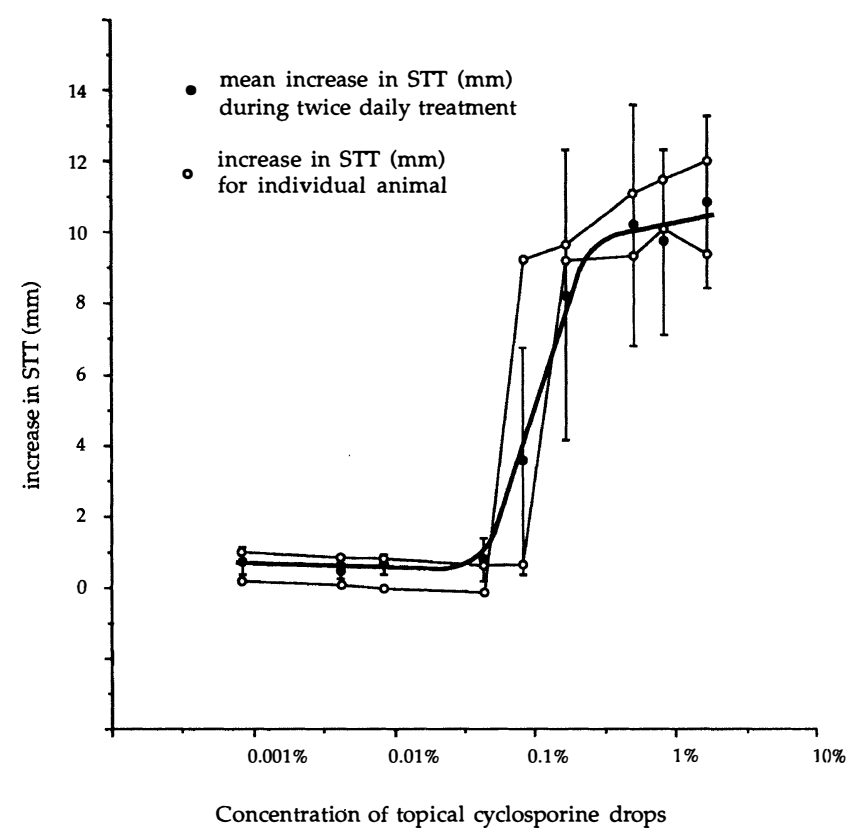

Fig. 4. Dose-response curve demonstrating variation in response to topical cyclosporine drops with cyclosporine concentration. STT, Schirmer tear test. 
infiltrate does not occur. This does not, however, preclude lymphocytes from playing a role in lacrimal gland regulation. A wide variety of peptide hormones and neuropeptides influence lacrimal gland function, and cytokines from lymphocytes within the normal lacrimal gland may play an important part in lacrimal stimulation.

Cyclosporine may also affect hormonal interactions with lacrimal tissue. The drug increases prolactin binding to lacrimal tissue,${ }^{39}$ in contrast to the situation in lymphocytes where cyclosporine competitively inhibits prolactin binding. ${ }^{40}$ Prolactin has been shown to inhibit peroxidase release in lacrimal tissue, an indicator of lacrimal secretion. ${ }^{41}$ Cyclophilin is a ligand for prolactin and as such an interaction between cyclosporine, prolactin and the lacrimal acinar prolactin receptor may be responsible for the lacrimogenic effects of the drug. ${ }^{42}$ Cyclosporine, FK-506 and rapamycin have been shown to inhibit prolactin gene expression in the pituitary gland ${ }^{43}$ but the apparent lack of systemic penetration of topical cyclosporine renders it unlikely that the pituitary is the site of action of topical cyclosporine. Inhibition of local prolactin production may, however, be important in drug-induced lacrimogenesis.

\section{THE PHARMACOKINETICS OF TOPICAL CYCLOSPORINE}

Inflammatory diseases of the ocular surface are the obvious indications for topical cyclosporine therapy. Drug penetration to the cornea and conjunctiva occurs readily following topical administration. The lipophilicity of cyclosporine renders the cornea a reservoir for the drug. As discussed above, canine $\mathrm{KCS}$ is another prime indication for the use of topical cyclosporine. Effects on lacrimation clearly require penetration of the drug to the lacrimal gland but the lipophilic nature of the molecule would facilitate such local tissue distribution. More complex are the problems associated with penetration of cyclosporine into the intraocular compartment for use in uveitis and the systemic spread of topically applied drug.

Cyclosporine in an oil base is retained by the cornea as a reservoir; this effect is accentuated by application in an ointment base. ${ }^{44}$ But is topically applied drug absorbed into the intraocular or systemic circulating compartment? While some reports document negligible serum levels of drug following topical application, ${ }^{45}$ other workers found significant circulating levels after topical application. ${ }^{46}$ These differences are likely to relate to the volume of fluid applied to the eye in small experimental animals, where considerable nasolacrimal overflow can give systemic absorption after mucosal penetration. These effects are likely to have flawed experiments in which topical cyclosporine was reported to have been efficacious in treating experimental posterior segment inflammatory disease. ${ }^{47}$

Similar problems can be seen comparing results documenting transcorneal penetration into intraocular compartments. Some workers find low levels of drug in intraocular compartments after topical administration $^{48-50}$ while others report significant drug levels in aqueous. ${ }^{51,52}$ Some differences relate to the vehicle in which the drug is presented while others are frankly inexplicable.

Variations in transcorneal cyclosporine penetration are, however, important if the drug is to be used for intraocular immunosuppression. Olive oil and corn oil appear to give little transcorneal penetration. Alpha-cyclodextrin has been shown in one in vivo human study to give therapeutic levels in aqueous humour after five applications one day before cataract surgery at which samples of aqueous were taken. ${ }^{53}$ The findings of this study are not corroborated by an in vitro investigation which failed to demonstrate increased transcorneal permeability with alpha-cyclodextrin as the vehicle compared with corn oil. Delivery of cyclosporine in liposomes alone or liposomes incorporated in collagen shields gave good intraocular penetration when compared with cyclosporine in corn oil in an in vivo rabbit model. ${ }^{54}$

At present topical cyclosporine is not regularly used to combat intraocular inflammation in the fields of either human or veterinary ophthalmology. Yet investigations of its use to combat corneal transplant rejection and in ocular surface inflammatory disease have been widespread.

\section{TOPICAL CYCLOSPORINE IN CORNEAL ALLOGRAFT REJECTION}

Corneal transplants are the most successful solid tissue grafts, with HLA tissue matching generally being considered non-essential. Nevertheless, rejection remains the most common cause of graft failure. ${ }^{55}$ High-risk keratoplasty involving a vascularised donor bed or as a consequence of previous graft failure requires intensive anti-inflammatory therapy. Topical corticosteroids are used both prophylactically and in the management of a rejection episode: systemic treatment may be added by oral medication or in an intravenous pulse regime. Adding topical cyclosporine to the anti-inflammatory regime is an important option in these high-risk situations.

Several experimental models of high-risk keratoplasty have been reported. In one model fullthickness skin grafts were exchanged between mouse strains after corneal grafting. Topical cyclosporine in a water-soluble galenic form dissolved in ethanol and chremophor was given five times daily. Mean survival time in treated grafts was 37 days 
compared with 26 days in control animals. ${ }^{56}$ This report used $5 \%$ cyclosporine while a previous study using a $1 \%$ concentration showed no effect prolonging graft survival. ${ }^{57}$ This is a somewhat surprising result given that the group showed the same concentration preventing rejection 1 year later in a different model without skin grafting. ${ }^{58}$ Giving 5\% cyclosporine five times daily, however, results in an overall administration of $3 \mathrm{mg} / \mathrm{kg}$ per day, a dose which could give systemic immunosuppression. Foets and colleagues ${ }^{45}$ discuss the relative importance of systemic versus local immunosuppression in their study of graft survival with topical cyclosporine. Given that cyclosporine administration in one eye failed to prevent graft rejection in the fellow eye, these workers considered that local and not systemic immunosuppression was occurring here, although plasma levels of cyclosporine were at immunosuppressive levels.

Other workers have shown that cyclosporine dissolved in the penetration enhancer azone acts to suppress graft rejection, although their study did not compare cyclosporine in oil with cyclosporine in azone. ${ }^{59}$ Similarly corneal allograft survival is prolonged with cyclosporine delivered in liposomes in the rat, with that particular study showing an increased survival of liposome-incorporated cyclosporine compared with the same dose of cyclosporine in olive oil. ${ }^{60}$ Even small advantages given by varied delivery systems are potentially important given the difficulty in providing adequate medication in highrisk allografts. Sometimes systemic cyclosporine treatment is the only sure way of preventing rejection. ${ }^{61}$

\section{TOPICAL CYCLOSPORINE IN OCULAR SURFACE INFLAMMATORY DISEASE}

In veterinary medicine the main indication for the use of cyclosporine is canine KCS, where the drug's lacrimogenic effects outweigh anti-inflammatory actions in importance. Ocular surface inflammatory

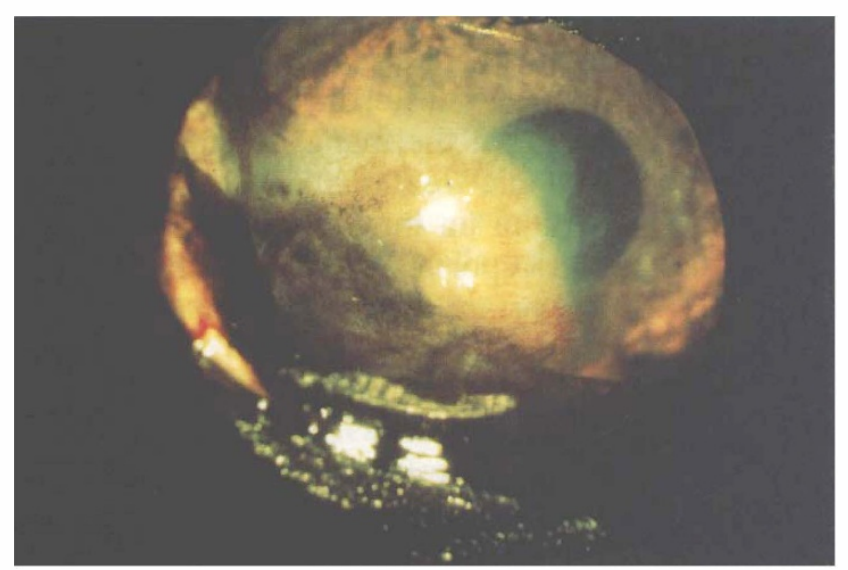

Fig. 5. Canine chronic superficial keratitis in a German shepherd dog.

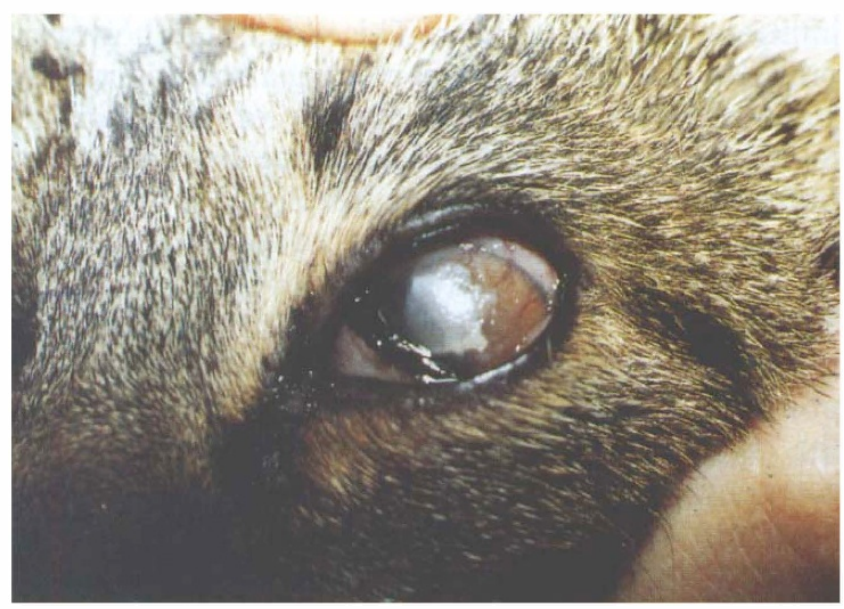

Fig. 6. Feline eosinophilic keratitis in a domestic shorthaired cat.

disease is also an indication for the use of topical cyclosporine, although canine KCS was initially the only indication mentioned on the drug data sheet in the UK. In the dog and cat two severe corneal inflammatory conditions occur: chronic superficial keratitis (CSK) in the dog (Fig. 5) and feline eosinophilic keratoconjunctivitis in the cat (FEKC) (Fig. 6). My doctoral studies involved immunocytochemical and histochemical characterisation of the former as well as evaluation of treatment regimes using topical dexamethasone and topical cyclosporine. The corneal lesion of CSK involves superficial stromal lymphocytic infiltration, with the predominant cell type being the $\mathrm{CD}^{+}$lymphocyte, many cells producing $\gamma$-interferon. ${ }^{62}$ Thus the disease would seem the ideal candidate for topical cyclosporine therapy. Indeed it is: my studies showed equivalent ameliorative actions on corneal lesions produced by topical cyclosporine and the standard therapy for the condition, topical steroid. ${ }^{33} \mathrm{~A}$ placebo controlled trial was not attempted for ethical reasons and since such a trial had already been reported showing that it was the drug and not vehicle which had the anti-inflammatory effects. ${ }^{63}$

Mooren's ulcer is not a recognised disease in the pet cat or dog population, neither are rheumatoidrelated peripheral corneal melts. On occasion dogs may present with apparently comparable disease (Fig. 7) but numbers of affected animals are so small that more than anecdotal reports are not possible. One would expect, nevertheless, that topical cyclosporine would be valuable in such cases, as it has been shown to be in human Mooren's ulcer and peripheral melts. ${ }^{64,65}$ Scleritis is seen in the dog, although not commonly (Fig. 8). A different spectrum of disease presentation is seen in the dog as compared with man: ischaemogenic vasculitis is exceptionally rare and thus sequelae such as scleromalacia perforans are almost never seen. Nevertheless, as is the case with man, ${ }^{66}$ topical cyclosporine 


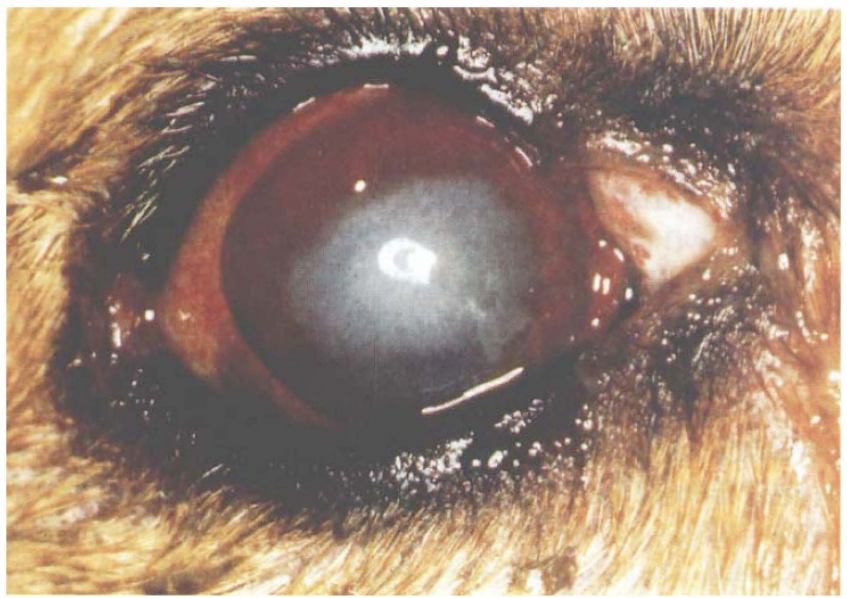

Fig. 7. Peripheral immune-mediated corneal disease in a German shepherd dog. Courtesy of Dr S. M. Crispin.

can be useful in the treatment of canine scleritis and episcleritis. A more common ocular surface disease in the dog where cyclosporine is indicated is canine plasmacytic conjunctivitis. ${ }^{67}$ While the cell phenotype, as demonstrated immunocytochemically here, is again predominantly the $\mathrm{CD}^{+}$lymphocyte, the term plasmacytic conjunctivitis remains since the original histology showed a mixed lymphocytic plasmacytic infiltrate. In this disease, as with CSK, long-term steroid treatment is indicated if cyclosporine is not used. The deleterious effects of steroidinduced glaucoma and cataract, as seen in man, do not appear to occur in dogs, even on life-long topical steroid treatment. However, subclinical adrenocortical suppression has been noted on long-term topical ocular steroid treatment in the dog. ${ }^{68}$ A change to topical cyclosporine might thus be appropriate given that to date no clinical systemic effects have been detected.

Note added in proof: Since the submission of this paper, the finding of reduction in lymphocyte proliferative responses in dogs on long-term treatment with topical $2 \%$ cyclosporine has been reported (Gilger BC, Andrews JA, Wilkie DA, Lairmore MD. Vet Comp Ophthalmol 1996;6:125-130). Initial find-

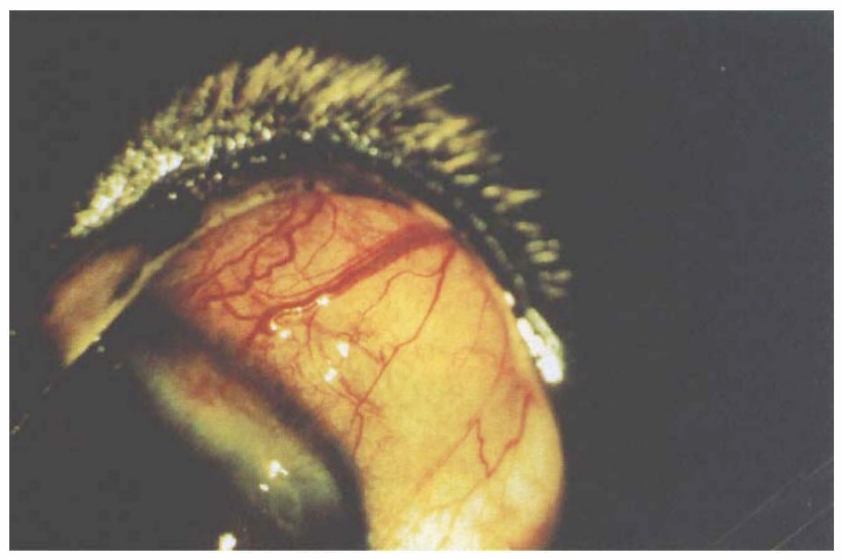

Fig. 8. Scleritis in a labrador retriever dog. ings from our laboratory suggest that the use of topical $0.2 \%$ cyclosporine ointment does not cause this suppression, although our studies have yet to be completed.

There is no human equivalent of chronic superficial keratitis, but FEKC has been suggested as a potential spontaneous animal model for vernal keratoconjunctivitis (VKC) ${ }^{69}$ There is some debate within the veterinary ophthalmology field over the efficacy of cyclosporine in this condition. The present author has not found cyclosporine to be particularly useful in FEKC while others have reported good therapeutic effects. ${ }^{70}$ Two problems occur with this disease. Firstly the incidence of the condition is significantly lower than that of canine CSK; it is thus a greater problem to amass a suitable number of cats for a randomised clinical trial. Secondly it may be that two diseases are presenting with similar clinical signs. While in some lesions eosinophils predominate and thus the term eosinophilic keratitis is appropriate, in other animals a wider spectrum of inflammatory cells infiltrate the conjunctiva and cornea and the term proliferative keratitis is preferred by some to include these animals. Considerable further investigation of this disease is required before comparative therapeutic implications can be defined.

Whatever the potential value of feline eosinophilic or proliferative keratitis as a spontaneous animal model for vernal keratoconjunctivitis, it is clear that topical cyclosporine is extremely effective in human VKC. ${ }^{71}$ While the number and size of giant papillae were not changed during treatment with $2 \%$ cyclosporine dissolved in corn oil, corneal punctate staining and Tarrantas' dots were markedly reduced as was photophobia. The mechanism of action of cyclosporine in $\mathrm{VKC}$ is unclear. It may be that cyclosporine has a direct effect on mast cells or perhaps it is more likely that the T-lymphocytedependent mast cells known to be increased in $\mathrm{VKC}^{72}$ are affected in an indirect manner through

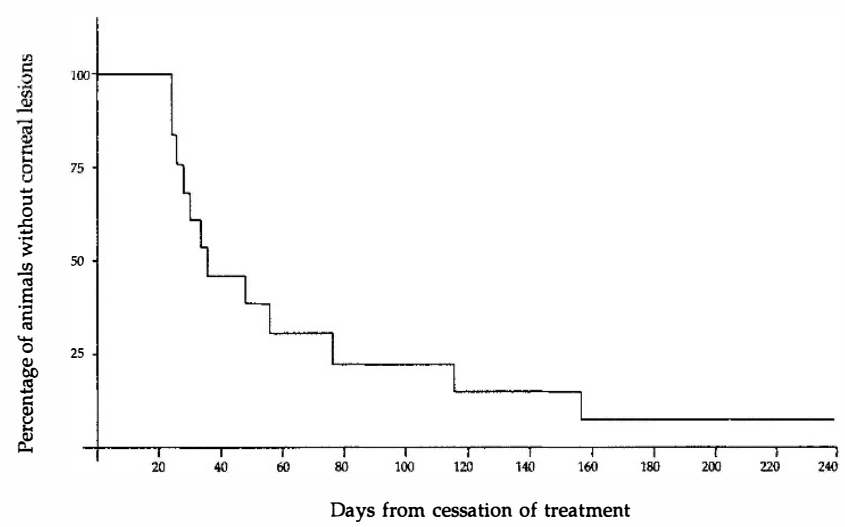

Fig. 9. Kaplan-Meier actuarial survival plot showing time to recurrence of corneal lesion in chronic superficial keratitis after cessation of cyclosporine therapy. 
inhibition of helper $\mathrm{T}$ cell action. Another study showed that, while $75 \%$ of children with VKC showed persistent improvement on cyclosporine therapy and $58 \%$ were symptom-free on treatment, only $25 \%$ were still free of the disease 2 months after treatment was discontinued. ${ }^{13}$ This drop off in symptom relief after treatment cessation was also shown in our study of cyclosporine in CSK: after 2 months $30 \%$ of dogs were still symptom free. ${ }^{33}$ The time to lesion recurrence is illustrated in the actuarial survival plot showing maintenance of a clear cornea after withdrawal of daily treatment (Fig. 9). An average of 45 days elapse after treatment cessation before lesion recurrence. Thus in both human and canine disease continual and potentially life-long treatment is required.

Such long-term treatment must, of course, raise questions regarding potential side effects. Local irritation was noted in a number of dogs when cyclosporine was used at $2 \%$ dissolved in olive oil, but the present author, using the drug equally effectively at $0.2 \%$ in corn oil or in an ointment formulation, saw no adverse effects over and above those transient irritative effects noted when any topical preparation is given to some dogs. Experimental studies on potential cyclosporine toxicity found superficial epithelial cell cratering and reduction of epithelial cell microvilli with $0.075 \%$ cyclosporine given every 30 minutes over a 5 hour period, although the penetrating agent alpha-cyclodextrin was included in the application so that it is somewhat difficult to assess which agent had the deleterious effect. ${ }^{73}$ The influence of topical cyclosporine in olive oil on corneal epithelial permeability has been determined in an in vivo study using human volunteers. $^{74}$ Prolonged ( $>1$ hour) ocular irritation was noted with the $2 \%$ cyclosporine formulation but also with olive oil alone. Experimental subjects developed punctate keratopathy which resolved after 24 hours. Epithelial permeability increased 7 times after application but again the cause of this change was the vehicle and not the agent itself. While the trials undertaken by Allergan showed untoward irritative effects with cyclosporine in their vehicle, the ointment base used by Schering-Plough for Optimmune, the veterinary product, appears to have had minimal deleterious effects.

With regard to systemic effects, generalised immunomodulation would depend on systemic absorption of the drug from topical drops. As discussed above there has been some controversy over the amount of drug absorbed after topical administration and changes in circulating lymphocyte activity and dynamics on topical treatment are currently under investigation in our laboratory. The key point to note at present is that no deleterious systemic signs have been noted in any of the considerable number of dogs on $2 \%$ or $0.2 \%$ topical treatment since cyclosporine began to be used by the veterinary ophthalmic community worldwide in 1990.

The effect of topical cyclosporine on herpetic disease of the external eye might well be of concern. It is known that topical steroid increases the severity of epithelial herpetic disease both in humans and in the cat, where feline herpes virus causes similar lesions to those seen in man. ${ }^{75}$ Stromal extension with potential for melting and corneal perforation is possible unless concurrent antiviral medication is given. When combined cyclosporine-trifluorothymidine treatment was given to animals in a rabbit experimental model of herpes simplex viral keratitis, stromal disease severity was considerably reduced, while anti-viral medication alone had little effect on what is now known to be an immunemediated lesion. ${ }^{76}$ Cyclosporine without antiviral cover was reported to result in increased epithelial disease, although data substantiating this claim were not shown. In the aforementioned study animals had been systemically sensitised to herpes simplex virus prior to intra-stromal challenge with virus. Iritis occurred in all animals and the intraocular inflammation was not ameliorated by the topical steroid. A second paper used a rabbit model with primary topical infection onto an abraded cornea. ${ }^{77}$ Here systemic cyclosporine potentiated stromal disease without exacerbating epithelial lesions, but given that animals would have been systemically immunosuppressed, the relevance of these findings to the topical use of cyclosporine is difficult to gauge. The prevalence of viral ocular surface disease in the dog is unknown: punctate ulcerative keratopathy in the dog (Fig. 10) is seen as an ocular surface inflammatory disease in which some animals are responsive to trifluorothymidine, suggesting a viral aetiology, while other animals do not respond to antiviral medication. Again cyclosporine is effective in ameliorating corneal signs in these latter animals.

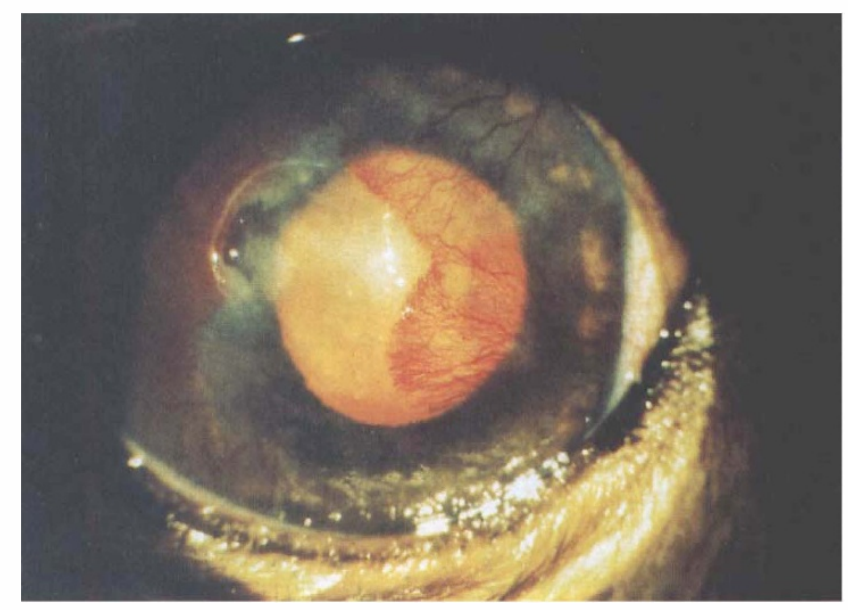

Fig. 10. Punctate ulcerative keratopathy in a dachshund. 
Given that long-term topical cyclosporine must to some degree compromise the immune status of the ocular surface are there deleterious effects increasing ocular surface bacterial flora? One paper, again from Kaswan's group, has examined results of bacterial isolation from over 30 dogs with KCS before and during topical cyclosporine treatment. ${ }^{78}$ Eyes responding well to treatment showed a reduction in bacterial isolation from the ocular surface. Eyes not responding to treatment with an increase in Schirmer tear test readings did not show a change in ocular surface bacterial population, indicating on the one hand that it was increased lacrimation rather than a direct antibiotic action of the drug which reduced bacterial isolation in responding dogs and on the other that cyclosporine-mediated ocular surface immunomodulation without increased lacrimation does not alter the ocular surface bacterial population. The antimycotic actions for which cyclosporine was initially developed $^{79}$ did not appear to reduce ocular surface yeast or fungal populations, but neither were these organisms recovered in greater numbers as might be expected in an immunosuppressive environment.

\section{TOPICAL CYCLOSPORINE FOR HUMAN USE: SOME CONCLUDING COMMENTS}

Topical cyclosporine would appear, then, to be a potent specific immunomodulator and lacrimogen widely and successfully used in the veterinary world both for canine KCS and for ocular surface inflammatory disease. Why then, it must be asked, has a commercial topical cyclosporine preparation hot been marketed for human use? Regulations regarding development of novel human medications are likely to be more stringent and thus restrictive than for veterinary products for the small animal market. The successful use of cyclosporine formulated in olive oil in the veterinary market as a 'homemade' product presumably eased the drug's passage to the market as a licensed veterinary preparation. Such widespread use of an unlicensed preparation would be far less acceptable in the human field. The initial problems experienced by Allergan with ocular irritation in early clinical trials may well have dampened enthusiasm for the drug, although these are likely to be related to the vehicle and not the drug itself. Although topical cyclosporine was first used in the veterinary field as a home-made preparation in various oil bases, the introduction of a commercial product (Optimmune, ScheringPlough) has brought with it standards of safety, efficacy and shelf-life. While cyclosporine has been seen by the veterinary ophthalmic community as nigh on a miracle cure for KCS the drug has not had the same take-up in Sjögren's syndrome, the human condition analogous in many ways to canine KCS.
So to conclude, given that topical cyclosporine is so widely used in canine KCS, what are the opportunities for using the drug in human dry eye and particularly in Sjögren's syndrome? Only a small number of studies on human subjects have been published. Laibovitz and colleagues treated 26 patients with KCS in a randomised double-masked placebo controlled single-crossover design study with a 2 week intertreatment washout period using $1 \%$ cyclosporine ointment (Refresh, Allergan) twice daily. Rose Bengal staining scores, as measured by the Bijsterveld method, ${ }^{80}$ were $55 \%$ improved in the group on cyclosporine after 1 week of treatment and improved to $85 \%$ above baseline after 6 weeks. The placebo group improved to $60 \%$ above baseline but cyclosporine results were statistically better at $p<0.05$. Tear film breakup times were also significantly improved as was tear lactoferrin and Schirmer tear test readings. In the washout period symptoms did not return to baseline values and thus only 9 patients met inclusion criteria for the second treatment period in this trial. ${ }^{81}$ Ironically of the 7 patients noting some intolerance to the medication, while 5 described itching or burning, 2 complained of overtearing! The present author has seen the same problem in dogs treated for mild canine KCS in which the problem turned from that of a dry eye to that of epiphora! Another stringently controlled trial of $2 \%$ cyclosporine in olive oil compared 15 patients treated with cyclosporine with 15 given vehicle alone. Again 2 months of treatment gave significant improvements in tear film breakup time and Rose Bengal staining, although interestingly Schirmer-1 test results were not significantly changed $(p>0.05)$. These authors concluded that cyclosporine modulated goblet cell function in KCS associated with secondary Sjögren's syndrome. ${ }^{82}$ This is, in the present author's opinion, an incorrect conclusion, but nevertheless the bottom line, if one might put it that way, is that topical cyclosporine is valuable in the treatment of the ocular signs associated with Sjögren's syndrome.

Surely from both these studies as well as from the wealth of veterinary experience there should be ample reason for further large trials and the rapid development of a commercial preparation for the human ophthalmic market? Patients wih diseases as diverse as Sjögren's syndrome, Mooren's ulcer and vernal keratoconjunctivitis would benefit, as have our dogs with KCS and CSK. It is hoped that this comparative review will speed that development process.

The author would like to acknowledge valuable discussions with Drs Barnett, Kaswan, Crispin and Sansom in the preparation of this paper. The author was funded through a research scholarship from the Wellcome Foundation during the work reported herein. The author has no commercial interest in cyclosporine or topical cyclosporine preparations.

Key words: Cyclosporine, Ke 


\section{REFERENCES}

1. Borel JF. Cyclosporine: historical perspectives. In: Kahan BD, editor. First international congress on cyclosporine. Orlando: Grune \& Stratton, 1984:3-13.

2. Borel JF, Feuer C, Gubler HU, Stahelin H. Biological effects of cyclosporin A: a new antilymphocyte agent. Agents Actions 1976;6:468-75.

3. Carne RY, Thiru S, McMaster P, Craddock GN, White DJG, Evans DB, et al. Cyclosporine A in patients receiving renal allografts from cadaveric donors. Lancet 1978;ii:1323-7.

4. Sigal NH, Dumont FJ. Cyclosporin A, FK-506 and rapamycin: pharmacological probes of lymphocyte signal transduction. Annu Rev Immunol 1992;10: 519-60.

5. Carne RY, White DJG, Pentlow BD, Rolles K, Syrakos T, Ohtawa T, et al. Cyclosporin A initially as the only immunosuppressant in 34 recipients of cadaveric organs: 32 kidneys, 2 pancreases and 2 livers. Lancet 1979; ii:1022-36.

6. Bougneres PF, Carel JC, Castano L. Factors associated with early remission of type 1 diabetes in children treated with cyclosporine. N Engl J Med 1988;318: 663-70.

7. Førre O, Bjerkhoel F, Salvessen CF. An open, controlled, randomised comparison of cyclosporine and azathioprine in the treatment of rheumatoid arthritis: a preliminary report. Arthritis Rheum 1987; 30:88-92.

8. Nussenblatt RB, Rodrigues MM, Wacker WB, Cevario SJ, Salinas-Carmona MC, Gery I. Cyclosporin A: inhibition of experimental autoimmune uveitis in rats. J Clin Invest 1981;67:1228-31.

9. Nussenblatt RB, Rook AH, Wacker WB, Palestine AG, Scher I, Gery I. Treatment of intraocular inflammatory disease with cyclosporin A. Lancet 1983;ii:235-8.

10. Bell TAG, Easty DL, McCullach KG. A placebocontrolled blind trial of cyclosporin-A in prevention of corneal graft rejection in rabbits. $\mathrm{Br} \mathrm{J}$ Ophthalmol 1982;66:303-8.

11. Kana JC, Hoffman F, Buchen R, Krolik A, Wiederholt M. Rabbit corneal allograft survival following topical administration of cyclosporin A. Invest Ophthalmol Vis Sci 1982;22:686-90.

12. Zhao J-C, Jin X-Y. Immunological analysis and treatment of Mooren's ulcer with cyclosporine A applied topically. Cornea 1993;12:481-8.

13. BenEzra D, Peter J, Brodsky M, Cohen E. Cyclosporine eye drops for the treatment of severe vernal keratoconjunctivitis. Am J Ophthalmol 1989;107:160-6.

14. Holland EJ, Chan C, Kuwabara T, Palestine AG, Rowseg IJ, Nussenblatt RB. Immunohistologic findings and results of treatment with cyclosporine in ligneous conjunctivitis. Am J Ophthalmol 1989;107:160-6.

15. Liegner JT, Yee RW, Wild JH. Topical cyclosporine therapy for ulcerative keratitis associated with rheumatoid arthritis. Am J Ophthalmol 1990;109:610-2.

16. Holland EJ, Olsen TW, Ketcham JM, Florine C, Krachmer JH, Purcell JJ, et al. Topical cyclosporin A in the treatment of anterior segment inflammatory disease. Cornea 1993;12:413-9.

17. Emmel EA, Vermeij CL, Durand DB, Higgins KM, Lacy E, Crabtree GR. Cyclosporine A specifically inhibits function of nuclear proteins involved in $\mathrm{T}$ cell activation. Science 1989;246:1617-20.
18. Banerji SS, Parsons JN, Tocci MJ. The immunosuppressant FK-506 specifically inhibits mitogen-induced activation of the IL-2 promoter and the isolated enhancer elements NFIL-2A and NF-AT1. Mol Cell Biol 1991;11:5074-87.

19. Liu J. FK506 and cyclosporin, molecular probes for studying intracellular signal transduction. Immunol Today 1993;14:290-5.

20. Sigal NH, Dumont F, Durette P, Sierkierka JJ, Peterson L, Rich $\mathrm{D}$, et al. Is cyclophilin involved in the immunosuppressive and nephrotoxic mechanism of action of cyclosporin A? J Exp Med 1991;173:619-28.

21. Clipstone NA, Fiorentino DF, Crabtree GR. Molecular analysis of the interaction of calcineurin with drug-immunophilin complexes. J Biol Chem 1994;269:26431-7.

22. McCaffrey PG, Perino BA, Soderling TR, Rao A. NFATp, a T lymphocyte DNA-binding protein that is a target for calcineurin and immunosuppressive drugs. J Biol Chem 1993;268:3747-52.

23. LeGrue SJ, Turner R, Weisbroth N, Dedman JR. Does the binding of cyclosporine to calmodulin result in immunosuppression? Science 1986;234:68-71.

24. Forrest MJ, Jewell ME, Koo GC, Sigal NH. FK-506 and cyclosporine A: selective inhibition of calcium ionophore induced polymorphonuclear leucocyte degranulation. Biochem Biopharmacol 1991;42:1221-8.

25. Shi YF, Shahai BM, Green DR. Cyclosporin A inhibits activation-induced cell death in $\mathrm{T}$ cell hybridomas and thymocytes. Nature 1989;339:625-6.

26. Kaswan RL, Martin CL, Chapman WL. Keratoconjunctivitis sicca: histopathological study of nictitating membrane and lacrimal glands from 28 canine cases. Am J Vet Res 1984;45:112-8.

27. Wieczorek R, Jakobiec FA, Sacks EH, Knowles DM. The immunoarchitecture of the normal human lacrimal gland: relevancy for understanding pathologic conditions. Ophthalmology 1988;95:100-9.

28. Jabs DA, Prendergast RA. Reactive lymphocytes in lacrimal gland and vasculitic renal lesions of autoimmune MRL/lpr mice express L3T4. J Exp Med 1987;166:1198-203.

29. Green K, Palmer SL, Bowen PA. Systemic cyclosporine increases tear flow in renal allograft recipients. Invest Ophthalmol Vis Sci 1994;35:2035.

30. Kaswan RL, Salisbury MA, Ward DA. Spontaneous canine keratoconjunctivitis sicca: a useful model for human keratoconjunctivitis sicca: treatment with cyclosporine eye drops. Arch Ophthalmol 1989;107: 1210-6.

31. Reilly L, Beech J. Bilateral keratoconjunctivitis in a horse. Eq Vet J 1994;26:171-2.

32. Collins BK, Johnson PJ, Moore CJ, Collier LL, Shaw MS. Immune-mediated keratoconjunctivitis sicca in a horse. Vet Comp Ophthalmol 1994;4:61-5.

33. Williams DL, Hoey A, Smitherman P. The use of topical cyclosporine and dexamethasone in the treatment of canine chronic superficial keratitis: a comparison of therapeutic effects. Vet Rec 1995;137:635-9.

34. Watanbe-Fukunaga R, Brannan CI, Copeland NG, Jenkins A, Nagata S. Lymphoproliferative disorder in mice explained by defects in Fas antigen that mediates apoptosis. Nature 1992;356:314-7.

35. Sato EH, Sulivan DA. Comparative influence of steroid hormones and immunosuppressive agents on autoimmune expression in lacrimal glands of a female mouse model of Sjögren's syndrome. Invest Ophthalmol Vis Sci 1994;35:2632-42. 
36. Dalavanga YA, Detrick B, Hooks JJ, Drosos AA, Moutsopoulos HM. Effect of cyclosporin A (CsA) on the immunopathological lesion of the labial salivary glands from patients with primary Sjögren's syndrome. Ann Rheum Dis 1987;46:89-92.

37. Jabs DA, Lee B, Burek CL, Saboori AM, Prendergast RA. Cyclosporine therapy suppresses ocular and lacrimal gland disease in MRL/MP-lpr/lpr mice. Invest Ophthalmol Vis Sci 1996;37:377-83.

38. Jackson PA, Kaswan RL, Meredith RE, Barrett PM. Chronic superficial keratitis in dogs: a placebo controlled trial of topical cyclosporine treatment. Prog Vet Comp Ophthalmol 1991;1:269-75.

39. Mircheff AK, Warren DW, Wood RL, Tortoriello PJ, Kaswan RL. Prolactin localisation, binding and effects on peroxidase release in rat exorbital lacrimal gland. Invest Ophthalmol Vis Sci 1992;33:641-50.

40. Russell DH, Matrisian L, Kibler R, Larson DF, Poulos $\mathrm{R}$, Magun BE. Prolactin receptors on human lymphocytes and their modulation by cyclosporine. Biochem Biophys Rev Commun 1984;121:899-906.

41. Kaswan RL, Salisbury MA, Mircheff AK, Glerow JP. Lacrimomimetic effects of cyclosporine. Invest Ophthalmol Vis Sci 1990;31:46.

42. Russell DH, Kibler R, Martrisian L, et al. Prolactin receptors on human $\mathrm{T}$ and $\mathrm{B}$ lymphocytes: antagonism of prolactin binding by cyclosporine. $\mathrm{J}$ Immunol 1985;134:3027-31.

43. Wera S, Belayew A, Martial JA. Rapamycin, FK506 and cyclosporine A inhibit human prolactin gene expression. FEBS Lett 1995;358:158-60.

44. Weingarten AJ, Ballard F, Jaffe J, Schwartz HJ. Ocular absorption and penetration following topical application of a $2 \%$ ointment prepared with a solution of cyclosporine in corn oil. Proc Eur Assoc Vet Pharmacol Ther, Edinburgh, August 1994.

45. Diaz-Llopis M, Menezo JL. Penetration of $2 \%$ cyclosporin eyedrops into human aqueous humour. Br J Ophthalmol 1988;73:600-3.

46. Bell TAG, Hunnisett AG. Cyclosporine A: tissue levels following topical and systemic administration to rabbits. Br J Ophthalmol 1986;70:852-5.

47. Nussenblatt RB, Dinning WJ, Fujikawa LS, Chan C-C, Palestine AG. Local cyclosporine therapy for experimental autoimmune uveitis in rats. Arch Ophthalmol 1985;103:1559-62.

48. Wiederholt M, Kossendrup D, Schultz W, Hoffmann F. Pharmacokinetics of topical cyclosporin A in the rabbit eye. Invest Ophthalmol Vis Sci 1986;27:519-24.

49. Kaswan RL. Intraocular penetration of topically applied cyclosporine. Transplant Proc 1988;20:650-5.

50. Mossteler MW, Gebbardt BM, Hamilton AM, Kaufman HE. Penetration of topical cyclosporine into the rabbit cornea, aqueous humour and serum. Arch Ophthalmol 1985;103:101-2.

51. Nussenblatt RB. The use of cyclosporine in ocular inflammatory disorders. Transplant Proc 1988;20: 114-21.

52. Foets B, Misoten L, Van der Veeren P, Goosens W. Prolonged survival of allogenic corneal grafts in rabbits treated with topically applied cyclosporin A: systemic absorption and local immunosuppressive effects. Br J Ophthalmol 1985;69:600-3.

53. Saito H, Shimazaki J, Yang Y-H, Toda I, Fujishima H. Application of $0.05 \%$ cyclosporin A dissolved in alphacyclodextrin in human eyes. Invest Ophthalmol Vis Sci 1994;35:2879.
54. Pleyer U, Elkins B, Rücken D, Lutz S, Grammer J, Chou J, et al. Ocular absorption of cyclosporin A from liposomes incorporated into collagen shields. Curr Eye Res 1994;13:177-81.

55. Alldredge OC, Krachmer JH. Clinical types of corneal transplant rejection: their manifestations, frequency, preoperative correlates and treatment. Arch Ophthalmol 1981;99:599-604.

56. Kana JS, Hoffmann F, Buchen R, Krolik A, Wiederholt M. Rabbit corneal allograft survival following topical administration of cyclosporin A. Invest Ophthalmol Vis Sci 1982;22:686-90.

57. Shepherd WFI, Coster DJ, Chin Fook T, Rice NSC, Jones BR. Effect of cyclosporin A on the survival of corneal grafts in rabbits. $\mathrm{Br} \mathbf{J}$ Ophthalmol 1980; 64:148-52.

58. Hunter PA, Wilhelmus KR, Rice NSC, Jones BR. Cyclosporin A applied topically to the recipient eye inhibits corneal graft rejection. Clin Exp Immunol 1981;45:173-9.

59. Newton C, Gebhardt BM, Kaufman HE. Topically applied cyclosporine in azone prolongs corneal allograft survival. Invest Ophthalmol Vis Sci 1988;29: 208-15.

60. Milani JK, Pleyer U, Dukes A, Chou HJ, Lutz S, Rückert D, Schmidt KH, Mondino BJ. Prolongation of corneal allograft survival with liposome-encapsulated cyclosporine in the rat eye. Ophthalmology 1993;100: 890-6.

61. Hill JC. Systemic cyclosporine in high risk keratoplasty. Ophthalmology 1994;101:128-33.

62. Williams DL. Histological and immunocytochemical analysis of canine chronic superficial keratitis. Invest Ophthalmol Vis Sci 1994;35:2016.

63. Jackson PA, Kaswan RL, Meredith RE, Barrett PM. Chronic superficial keratitis in dogs: a placebo-controlled trial of topical cyclosporine treatment. Prog Vet Comp Ophthalmol 1991;1:267-76.

64. Hill JC, Potter P. Treatment of Mooren's ulcer with cyclosporin A: a report of three cases. Br J Ophthalmol 1987;71:11-5.

65. Kuit PJ, Balen AThM, Stilma JS. Cyclosporin A in two cases of corneal peripheral melting syndrome. Doc Ophthalmol 1985;59:33-9.

66. Hoffman F, Widerholt M. Local treatment of necrotising scleritis with cyclosporin A. Cornea 1985;4:3-7.

67. Reed RA. Treatment of canine nictitans plasmacytic conjunctivitis with $0.2 \%$ cyclosporin ointment. J Small Anim Pract 1995;36:50-6.

68. Glaze MB, Crawford MA, Nachreiner RF, Casey HW, Nafe LA, Kearney MT. Ophthalmic corticosteroid therapy: systemic effects in the dog. J Am Vet Med Assoc 1988;192:73-5.

69. Crispin SM. Personal communication.

70. Reed RA, Barnett KC, Sansom J. Cyclosporin-responsive keratoconjunctivitis in the cat and horse. Vet Rec 1995;137:170-1.

71. Bleik JH, Tabbara KF. Topical cyclosporine in vernal keratoconjunctivitis. Ophthalmology 1991;98:1679-84.

72. Irani AM, Butrus SI, Tabbara KF, Schwartz LB. Human conjunctival mast cells: distribution of $\mathrm{MCr}$ and MCrc in vernal conjunctivitis and giant papillary conjunctivitis. J Allergy Clin Immunol 1990;86:34-40.

73. Kinai A, Alba RM, Takano T, Kopnayashi C, Nakajima A, Kurihara K, et al. The effect on the cornea of alpha-cyclodextrin vehicle for cyclosporine eye drops. Transplant Proc 1989;21:3150-2. 
74. Beníttez del Catillo JM, del Aguila C, Duran S, Hernandez J, Sánchez JG. Influence of topically applied cyclosporin A in olive oil on corneal epithelial permeability. Cornea 1994;13:136-40.

75. Nasisse MP, Guy JS, Davidson MG, Susman WA, Fairley NM. Experimental ocular herpes virus infection in the cat. Invest Ophthalmol Vis Sci 1989;30:1758-68.

76. Boisjoly HM, Woog JJ, Pavan-Langston D, Oark NH. Prophylactic topical cyclosporine in experimental herpetic stromal keratitis. Arch Ophthalmol 1984;102: 1804-7.

77. Meyers-Elliott RH, Chitjian PA, Billups CB. Effects of cyclosporine $\mathrm{A}$ on clinical and immunological parameters in herpes simplex keratitis. Invest Ophthalmol Vis Sci 1987;28:1170-80.
78. Salisbury MAR, Kaswan RL, Brown J. Microorganisms isolated from the corneal surface before and during cyclosporine treatment in dogs with keratoconjunctivitis sicca. Am J Vet Res 1995;56:880-4.

79. Kirland TN, Fierer J. Cyclosporine A inhibits Coccidiodes immitis in vitro and in vivo. Antimicrob Agents Chemother 1983;24:921-4.

80. van Bijsterveld OP. Diagnostic tests in the sicca syndrome. Arch Ophthalmol 1988;82:10-4.

81. Laibovitz RA, Sotsh S, Andriano K, O'Connell M, Silverman $\mathrm{MH}$. Pilot trial of cyclosporine $1 \%$ ophthalmic ointment in the treatment of keratoconjunctivitis sicca. Cornea 1993;12:315-23.

82. Gunduz K, Ozdemir O. Topical cyclosporin treatment of keratoconjunctivitis sicca in secondary Sjögren's syndrome. Acta Ophthalmol (Copenh) 1994;72:438-42. 